\title{
Aceitabilidade de doadores de sangue no hemocentro público do Recife, Brasil
}

\author{
Acceptance by blood donors of the public blood bank \\ in Recife, Brazil.
}

Fábia Michelle Rodrigues de Araújo ${ }^{1}$

Katia Virginia de Oliveira Feliciano ${ }^{1}$

Marina Ferreira de Medeiros Mendes ${ }^{1}$

${ }^{1}$ Instituto de Medicina Integral Prof. Fernando Figueira (IMIP). Rua dos Coelhos 300, Boa Vista. 50070-550 Recife PE.

fabiamra@yahoo.com.br

\begin{abstract}
This study evaluated the acceptance of blood donors concerning the donation stages (attendance, medical and nursing selection and collection) at the Recife public blood bank with emphasis on the attendance. A sample of 527 donors was obtained: each 19th person sequentially was invited to answer a questionnaire. Chi-square ( $x 2$ ) was used in the analysis. Of those interviewed, $81.4 \%$ were men, $81 \%$ were repeat donors, $50.3 \%$ were dissatisfied regarding the time spent in donation and $36.4 \%$ had difficulties in reaching the service. The firm acceptance given to the attendance was due mainly to the communication and the quality of treatment. Of statistical significance were women donors of higher educational level who asked for more information and men who had a more positive perception towards the selection process. The best evaluation was attributed to the collection sector. However, mention was made of impersonal treatment, persistence of doubts and the cursory nature of the medical interview. Attention focused on the donor requires that ongoing education should concentrate on the humanitarian formation of the professionals involved.
\end{abstract}

Key words Blood donors, User satisfaction, Quality of healthcare, Health service evaluation; Health evaluation
Resumo Este estudo avaliou a aceitabilidade de doadores em relação às etapas da doação de sangue (recepção, triagens de enfermagem e médica, e coleta) em hemocentro público do Recife, ressaltando o acolhimento. Obteve-se amostra de 527 doadores: em cada 19 pessoas que sequencialmente doaram sangue, a décima nona era convidada a responder um questionário. $\mathrm{Na}$ análise aplicouse o qui-quadrado $\left(\chi^{2}\right)$. Ao redor de $81,4 \%$ eram homens, $81,0 \%$ doadores de repetição, 50,3\% insatisfeitos com o tempo gasto na doação e 36,4\% com dificuldade de chegar ao serviço. A forte aceitabilidade do acolhimento adveio, sobretudo, da comunicação e da forma de tratamento. Mostraram significância estatística: mulheres e doadores com maior escolaridade pediram mais esclarecimentos e homens tiveram percepção mais positiva das triagens. A sala de coleta foi o setor melhor avaliado. Contudo, foram feitas referências à impessoalidade, à persistência de dúvidas e à rapidez da entrevista médica. A atenção centrada no doador requer que a educação continuada também contemple a formação humanitária dos profissionais.

Palavras-chave Doadores de sangue, Satisfação do usuário, Qualidade dos cuidados de saúde, Avaliação de serviços de saúde, Avaliação em saúde 


\section{Introdução}

A escassez de sangue representa um problema de extensão mundial, suscitando grande preocupação, inclusive, em países como os Estados Unidos, Austrália e Suécia ${ }^{1}$. Em uma situação de demanda crescente por sangue e hemoderivados, a tendência estacionária das doações no Brasil, cujo percentual tem correspondido à aproximadamente $1,70 \% \mathrm{da}$ população ${ }^{2}$, acentua a insuficiência dos estoques também encontrada noutros países em desenvolvimento $^{3}$. Nos últimos anos, estudos sobre a percepção dos doadores de sangue relacionada ao atendimento na doação pretendem aproximar as unidades hemoterápicas aos seus contextos socioculturais, fornecendo recomendações para o enfrentamento dos desafios de aumentar a captação de doadores e a regularidade da doação ${ }^{4-7}$.

A percepção do usuário na avaliação das políticas públicas governamentais difundiu-se, no Brasil, a partir dos anos 90, mas vem adquirindo importância como instrumento de gestão desde 2002, quando o Sistema Nacional de Avaliação da Satisfação dos Usuários dos Serviços Públicos elaborou o Instrumento Padrão de Pesquisa de Satisfação (IPPS) para apoiar a institucionalização da pesquisa avaliativa de satisfação. Os indicadores do IPPS combinam elementos de metodologias de medição da qualidade do serviço, as quais definem a satisfação do usuário em função da diferença entre expectativa e desempenho ${ }^{8}$. Na busca continuada por melhoria, hemocentros brasileiros utilizam o IPPS para monitorar o nível de satisfação dos doadores ${ }^{7}$.

A visão dos doadores permite conhecer as suas necessidades e a qualidade percebida do atendimento, sendo um meio fundamental para identificar os aspectos que facilitam ou impedem os serviços de alcançarem os resultados previstos ${ }^{4,5,9}$. Para Donabedian ${ }^{10}$, a qualidade diz respeito aos atributos desejáveis para os serviços de saúde, e a aceitabilidade é um de seus componentes, traduzindo a conformidade da oferta aos valores e expectativas dos usuários. O conceito de aceitabilidade é multifacetado e pressupõe a influência dos padrões culturais nas apreciações individuais, sobretudo, acerca da competência técnica, acesso a cuidado, relações interpessoais, comunicação e características do local de prestação do serviço. As distintas concepções ou a ênfase diferenciada nos elementos constituintes da melhor qualidade condicionam os parâmetros e os critérios que serão utilizados na avaliação ${ }^{11-13}$.

No âmbito da consolidação de uma política de humanização para o País, as relações inter- pessoais e a comunicação têm merecido cuidado diferenciado ${ }^{14}$, com o acolhimento de profissionais e funcionários representando elemento central quando usuários avaliam a qualidade da atenção ${ }^{4-7,11-13}$. O acolhimento é uma maneira dialógica de interação que deve ser praticada em todas as conversações desenvolvidas em um serviço de saúde, significando abertura de espaço para o outro $^{15}$. Constitui-se, portanto, em um dispositivo indispensável para construir uma aproximação consciente e direcionada à satisfação das necessidades de uma perspectiva centrada na pessoa $^{15,16}$. A qualidade humana do serviço prestado pelos hemocentros é um direito da cidadania que, certamente, repercute na disponibilidade de tornar-se um doador regular ${ }^{4-6}$.

Em 2004, 53,5\% dos doadores no Brasil e $52,6 \%$ da região Nordeste já tinham doado cinco ou mais vezes em suas vidas ${ }^{17}$. Todavia, semelhante a outros países, persiste a necessidade do desenvolvimento sistemático de estratégias que estimulem os doadores de retorno a doarem com mais regularidade ${ }^{1,18,19}$. Embora seja preciso empreender esforços na captação de pessoas sem antecedentes de doação, os doadores regulares possuem duas vantagens sobre aqueles de primeira vez ou que fizeram apenas uma doação: oferecem um suprimento de sangue estável e seguro, já que apresentam consistentemente uma menor inaptidão sorológica, bem como contribuem para a redução de custos associados ao recrutamento de novos doadores ${ }^{6}$.

Em um contexto no qual urge aumentar a quantidade e a qualidade do sangue disponível, a produção científica brasileira e internacional é ainda modesta no tocante às apreciações dos doadores sobre aspectos que mostram o respeito e a consideração presentes no atendimento ${ }^{4-6}$. Por isso, neste estudo analisou-se a aceitabilidade de doadores relacionada às etapas da doação de sangue, no hemocentro público da cidade do Recife, destacando elementos do acolhimento. $\mathrm{Na}$ pretensão de aumentar a capacidade da avaliação de contribuir para um atendimento cada vez mais próximo das necessidades e expectativas dos doadores, buscou-se conhecer as justificativas para os julgamentos emitidos ${ }^{20}$.

\section{Métodos}

Estudo com delineamento transversal realizado entre 21 de janeiro e 30 de maio de 2008, em uma amostra de 527 doadores de sangue do Hemocentro Recife da Fundação de Hematologia e Hemote- 
rapia de Pernambuco (Hemope), única unidade hemoterápica pública de apoio à rede de serviços de saúde do Recife e Região Metropolitana. Definiu-se como universo do estudo o total de pessoas que doou sangue durante a coleta de dados. $\mathrm{O}$ tamanho da amostra foi calculado estimando $10 \%$ de avaliações negativas do processo de doação de sangue, segundo pesquisa efetuada na instituição ${ }^{7}$ em 2007, nível de confiança de $95 \%$ e erro de $2,5 \%$.

Conforme a legislação vigente, o processo de doação obedece ao seguinte fluxo: (a) recepção entrega de documento com foto e informações de dados pessoais; (b) triagem de enfermagem aferição de sinais vitais, peso e altura, além de contagem da hemoglobina; (c) triagem médica entrevista padronizada que permite, juntamente com os resultados da etapa prévia, definir a elegibilidade do candidato à doação; (d) lanchonete - oferta de alimentos antes de doar; (e) sala de coleta - punção venosa com retirada do sangue mediante o uso de material descartável; e, (f) lanchonete - lanche após a doação. O doador de sangue precisa gozar de boa saúde, ter idade entre 18 e 65 anos e peso acima de 50 quilos $^{21}$.

Com base numa listagem nominal, construída em cada turno da coleta de dados, a amostragem de conveniência foi iniciada com o primeiro doador que finalizou a doação de sangue no começo do turno, depois, de acordo com intervalo fixo, a décima nona pessoa era convidada a responder o questionário. Houve 44 recusas (não desejava participar, não tinha tempo) e duas exclusões (problema cognitivo visível e dispensa da bolsa por inadequação clínica). Nesses casos, o intervalo previsto para a "fração da amostra" foi contado a partir do doador que recusou ou foi excluído. Ocorreram 13 perdas (aceitaram participar, mas não foram localizados após doação).

Uma versão preliminar do questionário, com algumas questões abertas, foi aplicada junto a 50 doadores, visando uma primeira aproximação às justificativas para as respostas das perguntas de estimação, as quais mediante uma escala indicavam, para cada item, um grau de intensidade decrescente ${ }^{20}$. Utilizou-se gravador para registrar as respostas às questões abertas que foram transcritas na íntegra. Este foi ligado desde o início da entrevista para não interferir na interação entrevistador-entrevistado. Na versão final as perguntas abertas foram transformadas em semiabertas, contemplando as categorias de respostas mais frequentes e a alternativa "outras" para permitir a expressão de opiniões não previstas.

Contando com uma pessoa de suporte na amostragem, uma das autoras realizou a coleta de dados após o término da doação, em cinco dos seis dias de funcionamento do serviço em uma sala cedida pela instituição, cobrindo 43 turnos da manhã e 37 da tarde para obter amostra representativa. Constaram do questionário: características sociais e demográficas, antecedentes de doação, acesso ao hemocentro, tempo gasto na doação, forma de tratamento, comunicação e confiança no atendimento. As três últimas categorias conforme as etapas da doação: recepção, triagens de enfermagem e médica, e coleta. Para estimular respostas espontâneas, não foram oferecidas ao doador as alternativas já contempladas nas perguntas semiabertas relacionadas às justificativas das percepções. Foram tomados os mesmos cuidados do estudo piloto acerca da gravação e da transcrição das respostas.

As respostas para perguntas pré-codificadas com opção "outras" foram listadas e codificadas. Construiu-se matriz com programa Epi-Info 6.04, procedendo-se cuidadosa limpeza dos dados. Para cada componente avaliado, após análise prévia, as percepções foram agrupadas em três categorias: "ótimo/ bom”, "regular" e "ruim/ péssimo" para tratamento recebido; "muito grande/ grande", "regular" e "pequena/ nenhuma" para inteligibilidade, esclarecimento de dúvidas e confiança; "muito satisfeito/ satisfeito", "pouco satisfeito" e "insatisfeito/ muito insatisfeito" quanto à informação fornecida, sendo analisadas por etapa da doação, turno de trabalho, sexo, antecedentes de doação e escolaridade.

Utilizou-se o qui-quadrado ou o teste exato de Fisher, quando pertinente, para avaliar a existência de diferenças significativas, com um nível de confiança de 95\%. O termo "tendências" foi usado para resultados em que se esboçam diferenças sem significância estatística. $\mathrm{Na}$ apresentação, optou-se por inserir no texto os resultados que indicavam diferenças significativas e tendências. Merece destaque a possibilidade de ocorrência de flutuações atribuíveis ao pequeno número de doadores em algumas subcategorias de respostas. Apesar do tamanho da amostra permitir a obtenção de dados importantes sobre o processo avaliado, não foi suficiente para o estudo de subcategorias de respostas que apresentaram prevalência muito baixa.

Ao tratar deste hemocentro, por um lado delineamos um perfil que possui singularidades, por outro acreditamos que os resultados encontrados podem fornecer subsídios para outros serviços hemoterápicos aprimorarem seus vínculos com os doadores. O projeto foi aprovado pelo Comitê de Ética em Pesquisa do Hemope 
em 31/10/2007. No estudo piloto e na coleta de dados, os participantes assinaram o termo de consentimento livre e esclarecido.

\section{Resultados}

Ao redor de $81,4 \%$ dos entrevistados eram homens, com mediana de idade de 32 anos (amplitude entre 18 e 61 anos); a mediana de escolaridade era de 11 anos (distribuição entre 0 e 16 anos), sendo que $0,8 \%$ nunca estudaram e $9,5 \%$ concluíram curso superior. Aproximadamente 38,9\% eram solteiros e $75,9 \%$ integravam a população economicamente ativa. Metade residia no Recife, $57,3 \%$ utilizaram transporte público coletivo, com mediana de tempo gasto para chegar ao hemocentro de 30 minutos (um mínimo de 2 e máximo de 180 minutos). O deslocamento apresentou dificuldade para 36,4\%, sendo "regular" e "grande" para, respectivamente, $18,8 \%$ e $4,7 \%$. Dezenove por cento eram doadores de primeira vez e $56,4 \%$ doaram de forma espontânea. Para 14,1\% o tempo gasto na doação foi "muito grande/ grande", tendo sido "regular" para 35,6\%.

Entre $93,5 \%$ e $96,4 \%$ dos doadores receberam tratamento "ótimo" ou "bom" nas etapas da doação, estando o conceito "ótimo" mais relacionado à sala de coleta (SC) e menos à triagem de enfermagem (TE). Com relação à qualidade do tratamento predominaram as opiniões acerca da educação/cordialidade do profissional, mais frequente na SC e menos na triagem médica (TM), e do bom atendimento, maior na recepção. $\mathrm{O}$ atendimento rotineiro foi importante na TE e TM, sendo o cuidado valorizado, particularmente, na TM e SC. Outros aspectos positivos foram: sentir-se bem e atendimento rápido na $\mathrm{SC}$ e ausência de burocracia na recepção. Mencionaram-se características negativas como a falta de cordialidade na TE e a rapidez da entrevista médica (Tabela1). A menção ao tratamento "ótimo" na TE foi significativamente maior entre os homens $(p=0,049)$, existindo tendência na TM para ser mais citado pelos doadores de primeira vez $(\mathrm{p}=0,088)$.

O tratamento foi "regular", sobretudo, na TE e TM. Prevaleceu a percepção de desatenção/falta de cordialidade dos profissionais, seguida de atendimento rotineiro. (Tabela 1). A compreensão de que faltou educação/cordialidade foi generalizada entre os poucos doadores que sentiram o tratamento recebido como "ruim/péssimo".

Percentual maior de doadores $(35,1 \%)$ recebeu algum tipo de informação na recepção e menor $(17,8 \%)$ na TE. Praticamente não houve insatisfação com a informação fornecida, estando a maior concentração de "muito satisfeito" na SC e a menor na TE. A justificativa mais comum para a satisfação na recepção e TE foi o recebimento de informação apropriada. Destacaramse, na TM, esclarecimento de dúvidas e atitude de cuidado, embora esta última tenha sido mais associada à $\mathrm{SC}$, em relação à qual os doadores ainda revelaram-se satisfeitos pela aquisição de conhecimento. Outras opiniões positivas foram: sentir-se bem na recepção, satisfação profissional na TE e o simples fato de informar na SC (Tabela 2). Escassos doadores ficaram "pouco satisfeitos" ou "insatisfeitos", especialmente na recepção, porque receberam informação incompleta ou incorreta e faltou atenção/cordialidade.

Uma proporção maior de doadores $(27,5 \%)$ tentou esclarecer as dúvidas na SC e uma menor $(15,9 \%)$ na TM. A disponibilidade "muito grande" ou "grande" para prestar esclarecimento variou de $77,2 \%$ na TE a $94,5 \%$ na SC, sendo "muito grande" principalmente na SC e TM. Em todos os setores a educação/cordialidade, mais relacionada à TM e recepção, foi um indicativo da disponibilidade do profissional; seguida pela presteza para responder as perguntas. Ressaltaram-se a clareza da informação na TE e recepção e o esclarecimento de dúvidas na TM e SC. A competência profissional destacada na TM e SC foi outro aspecto positivo (Tabela 3 ). Observou-se diferença estatisticamente significativa na TE $(\mathrm{p}=0,009)$ e SC $(p=0,044)$ e tendência na recepção $(p=0,091)$ para as mulheres, bem como na recepção $(p=0,002)$, TM $(p=0,023)$ e SC $(p=0,017)$ para os doadores com maior nível de escolaridade, solicitarem mais esclarecimento de dúvidas.

A TE e a recepção apresentaram os maiores níveis de disponibilidade "regular", sobretudo, porque os profissionais não foram educados/ cordiais e o atendimento foi rotineiro (Tabela 3 ). Os pouquíssimos doadores que consideraram "pequena/ nenhuma" a disponibilidade para esclarecer dúvida se referiram à falta de atenção/ cordialidade.

Entre $85,8 \%$ e $88,6 \%$ dos doadores manifestaram uma confiança "muito grande" ou "grande" no atendimento, estando o conceito "muito grande" mais associado à SC. Os principais motivos da confiança foram: competência profissional, principalmente na TE; educação/cordialidade, maior na SC e menor na TM, e confiança na instituição, mais citada na TE. A compreensão da vivência do doador foi o aspecto mais valorizado na SC, sendo referida exclusivamente neste setor. 
Tabela 1. Percepção dos doadores sobre o tratamento recebido em distintas etapas da doação de sangue. Hemocentro Recife, Brasil, 2008

\begin{tabular}{|c|c|c|c|c|c|c|c|c|}
\hline \multirow[t]{2}{*}{ Tratamento } & \multicolumn{2}{|c|}{ Recepção } & \multicolumn{2}{|c|}{$\begin{array}{c}\text { Triagem de } \\
\text { Enfermagem }\end{array}$} & \multicolumn{2}{|c|}{$\begin{array}{l}\text { Triagem } \\
\text { Médica }\end{array}$} & \multicolumn{2}{|c|}{$\begin{array}{l}\text { Sala de } \\
\text { coleta }\end{array}$} \\
\hline & $\mathrm{n}^{\circ}$ & $\%$ & $n^{\circ}$ & $\%$ & $\mathrm{n}^{\circ}$ & $\%$ & $n^{\circ}$ & $\%$ \\
\hline \multicolumn{9}{|l|}{ Tratamento recebido } \\
\hline Ótimo & 322 & 61,1 & 286 & 54,2 & 326 & 61,8 & 366 & 69,5 \\
\hline Bom & 186 & 35,3 & 207 & 39,3 & 168 & 31,9 & 142 & 26,9 \\
\hline Regular & 17 & 3,2 & 31 & 5,9 & 29 & 5,5 & 17 & 3,2 \\
\hline Ruim & 1 & 0,2 & 2 & 0,4 & 4 & 0,8 & 1 & 0,2 \\
\hline Péssimo & 1 & 0,2 & 1 & 0,2 & 0 & 0,0 & 1 & 0,2 \\
\hline Ótimo/bom & \multicolumn{2}{|c|}{$\mathrm{n}=508$} & \multicolumn{2}{|c|}{$\mathrm{n}=493$} & \multicolumn{2}{|c|}{$\mathrm{n}=494$} & \multicolumn{2}{|c|}{$\mathrm{n}=508$} \\
\hline Bom atendimento & 262 & 51,6 & 182 & 36,9 & 96 & 19,4 & 142 & 27,9 \\
\hline Educado/cordial & 177 & 33,6 & 208 & 42,2 & 143 & 28,9 & 268 & 52,7 \\
\hline Perguntas/informações necessárias & 7 & 1,4 & 18 & 3,6 & 182 & 36,8 & 5 & 1,0 \\
\hline Atitude de cuidado & 0 & 0,0 & 20 & 4,1 & 70 & 14,2 & 61 & 12,0 \\
\hline Atendimento rotineiro & 10 & 2,0 & 107 & 21,7 & 78 & 15,8 & 17 & 3,3 \\
\hline Profissional competente & 23 & 4,5 & 59 & 12,0 & 21 & 4,2 & 125 & 24,6 \\
\hline Procedimento indolor/ pouco doloroso & 0 & 0,0 & 5 & 1,0 & 0 & 0,0 & 55 & 10,8 \\
\hline Atendeu logo & 172 & 33,9 & 51 & 10,3 & 0 & 0,0 & 0 & 0,0 \\
\hline Outros aspectos positivos & 53 & 10,4 & 23 & 4,7 & 33 & 6,7 & 66 & 13,0 \\
\hline Aspectos negativos & 18 & 3,5 & 38 & 7,7 & 27 & 5,5 & 8 & 1,6 \\
\hline Regular & \multicolumn{2}{|c|}{$\mathrm{n}=17$} & \multicolumn{2}{|c|}{$\mathrm{n}=31$} & \multicolumn{2}{|c|}{$\mathrm{n}=29$} & \multicolumn{2}{|c|}{$\mathrm{n}=17$} \\
\hline Não foi educado/cordial & 12 & 70,6 & 21 & 67,7 & 19 & 65,5 & 11 & 64,7 \\
\hline Demorou a atender & 3 & 17,6 & 1 & 3,2 & 0 & 0,0 & 0 & 0,0 \\
\hline Atendimento lento & 1 & 5,9 & 0 & 0,0 & 0 & 0,0 & 2 & 11,7 \\
\hline Insuficiência de profissionais & 2 & 11,7 & 0 & 0,0 & 0 & 0,0 & 0 & 0,0 \\
\hline Atendimento rotineiro & 0 & 0,0 & 9 & 29,0 & 4 & 13,8 & 7 & 41,2 \\
\hline Não realizou atendimento rotineiro & 0 & 0,0 & 3 & 9,7 & 0 & 0,0 & 0 & 0,0 \\
\hline Não teve espaço de expressão & 0 & 0,0 & 0 & 0,0 & 5 & 17,2 & 0 & 0,0 \\
\hline Não fez perguntas necessárias & 0 & 0,0 & 0 & 0,0 & 3 & 10,3 & 0 & 0,0 \\
\hline Faltou habilidade & 0 & 0,0 & 0 & 0,0 & 0 & 0,0 & 3 & 17,6 \\
\hline
\end{tabular}

Nota: em cada faixa de percepção, várias razões foram apresentadas pelos doadores para a percepção referida, motivo pelo qual a soma é superior a $100 \%$.

Também foram positivos: experiência prévia na SC e TE, confiança no material utilizado na SC e esclarecimento de dúvidas na TM (Tabela 4).

A confiança "regular" foi um pouco mais comum na TE. A falta de educação/cordialidade representou a razão mais importante desse sentimento na TE e TM. Também faltou informação apropriada ao doador na TE e houve descontentamento com a rapidez da entrevista na TM. O temor diante da situação foi marcante na SC, sendo mencionado apenas neste setor. Ainda foram negativos: a falta de atenção/cordialidade na TE e TM, a falta de informação na TE e a rapidez da entrevista médica (Tabela 4). O pequeno percentual de doadores com confiança "pequena/ nenhuma" no atendimento, embora com variações na frequência, apresentou um repertório de respostas semelhantes àqueles com confiança "regular".

\section{Discussão}

Os resultados mostraram uma forte aceitabilidade dos doadores acerca dos elementos do acolhimento investigados, estando uma maior percepção positiva relacionada à forma de tratamento e ao modo e conteúdo da informação. Gomes et al. ${ }^{22}$ consideram que a ótica dos usuários sobre a qualidade da assistência é um dos indicadores centrais para avaliar a adesão aos serviços. No entanto, chamam atenção que tendo como base a experiência e a subjetividade, a avaliação positiva tanto pode se referir realmente à boa qualidade do atendimento prestado, como traduzir as baixas expectativas quanto aos serviços públicos.

A compreensão de que o doador realiza uma ação que pode ser autoavaliada como altruísta e benéfica à sociedade demarca a diferença na sua 
Tabela 2. Grau de satisfação dos doadores com a informação recebida em distintas etapas da doação de sangue. Hemocentro Recife, Brasil, 2008

\begin{tabular}{|c|c|c|c|c|c|c|c|c|}
\hline \multirow{2}{*}{ Grau de satisfação } & \multicolumn{2}{|c|}{ Recepção } & \multicolumn{2}{|c|}{$\begin{array}{c}\text { Triagem de } \\
\text { Enfermagem }\end{array}$} & \multicolumn{2}{|c|}{$\begin{array}{l}\text { Triagem } \\
\text { Médica }\end{array}$} & \multicolumn{2}{|c|}{$\begin{array}{c}\text { Sala de } \\
\text { coleta }\end{array}$} \\
\hline & $\mathrm{n}^{\circ}$ & $\%$ & $\mathrm{n}^{\circ}$ & $\%$ & $n^{\circ}$ & $\%$ & $n^{\circ}$ & $\%$ \\
\hline Recebeu informação & 185 & 35,1 & 94 & 17,8 & 107 & 20,3 & 122 & 23,1 \\
\hline \multicolumn{9}{|l|}{ Informação deixou doador: } \\
\hline Muito satisfeito & 70 & 37,8 & 30 & 31,9 & 46 & 43,0 & 62 & 50,8 \\
\hline Satisfeito & 108 & 58,4 & 63 & 67,0 & 61 & 57,0 & 59 & 48,4 \\
\hline Pouco satisfeito & 4 & 2,2 & 1 & 1,1 & 0 & 0,0 & 1 & 0,8 \\
\hline Insatisfeito & 3 & 1,6 & 0 & 0,0 & 0 & 0,0 & 0 & 0,0 \\
\hline Muito insatisfeito & 0 & 0,0 & 0 & 0,0 & 0 & 0,0 & 0 & 0,0 \\
\hline Muito satisfeito/satisfeito & \multicolumn{2}{|c|}{$\mathrm{n}=178$} & \multicolumn{2}{|c|}{$\mathrm{n}=93$} & \multicolumn{2}{|c|}{$\mathrm{n}=107$} & \multicolumn{2}{|c|}{$\mathrm{n}=121$} \\
\hline Informação apropriada ao doador & 87 & 48,9 & 46 & 49,5 & 23 & 21,5 & 19 & 15,7 \\
\hline Adequação técnica da informação & 27 & 15,2 & 6 & 6,4 & 16 & 14,9 & 7 & 5,8 \\
\hline Clareza da informação & 13 & 7,3 & 12 & 12,9 & 5 & 4,7 & 7 & 5,8 \\
\hline Reforçou conhecimentos & 25 & 14,0 & 10 & 10,7 & 8 & 7,5 & 14 & 11,6 \\
\hline Adquiriu conhecimentos & 11 & 6,2 & 11 & 11,8 & 18 & 16,8 & 29 & 24,0 \\
\hline Esclareceu dúvidas & 29 & 16,3 & 11 & 11,8 & 30 & 28,0 & 13 & 10,7 \\
\hline Educado/cordial & 10 & 5,6 & 13 & 14,0 & 8 & 7,5 & 6 & 5,0 \\
\hline Atitude de cuidado & 1 & 0,6 & 0 & 0,0 & 25 & 23,4 & 34 & 28,1 \\
\hline Outros aspectos & 17 & 9,5 & 13 & 14,0 & 3 & 0,3 & 19 & 15,7 \\
\hline
\end{tabular}

Nota: várias razões foram apresentadas pelos doadores para a satisfação referida, motivo pelo qual a soma é superior a 100\%.

Tabela 3. Percepção dos doadores sobre a disponibilidade para esclarecer dúvidas em distintas etapas da doação de sangue. Hemocentro Recife, Brasil, 2008

\begin{tabular}{|c|c|c|c|c|c|c|c|c|}
\hline \multirow{2}{*}{$\begin{array}{c}\text { Disponibilidade } \\
\text { para esclarecer dúvidas }\end{array}$} & \multicolumn{2}{|c|}{ Recepção } & \multicolumn{2}{|c|}{$\begin{array}{l}\text { Triagem de } \\
\text { Enfermagem }\end{array}$} & \multicolumn{2}{|c|}{$\begin{array}{l}\text { Triagem } \\
\text { Médica }\end{array}$} & \multicolumn{2}{|c|}{$\begin{array}{l}\text { Sala de } \\
\text { coleta }\end{array}$} \\
\hline & $\mathrm{n}^{\mathrm{o}}$ & $\%$ & $\mathrm{n}^{\circ}$ & $\%$ & $n^{\circ}$ & $\%$ & $n^{\circ}$ & $\%$ \\
\hline Tentou esclarecer dúvidas & 88 & 16,7 & 92 & 17,4 & 84 & 15,9 & 145 & 27,5 \\
\hline \multicolumn{9}{|l|}{ Disponibilidade para esclarecer dúvidas: } \\
\hline Muito grande & 23 & 26,1 & 20 & 21,7 & 33 & 39,3 & 61 & 42,1 \\
\hline Grande & 48 & 54,6 & 51 & 55,5 & 42 & 50,0 & 76 & 52,4 \\
\hline Regular & 16 & 18,2 & 19 & 20,6 & 6 & 7,1 & 7 & 4,8 \\
\hline Pequena & 1 & 1,1 & 1 & 1,1 & 1 & 1,2 & 1 & 0,7 \\
\hline Nenhuma & 0 & 0,0 & 1 & 1,1 & 2 & 2,4 & 0 & 0,0 \\
\hline Muito grande/grande & \multicolumn{2}{|c|}{$\mathrm{n}=71$} & \multicolumn{2}{|c|}{$\mathrm{n}=71$} & \multicolumn{2}{|c|}{$\mathrm{n}=75$} & \multicolumn{2}{|c|}{$\mathrm{n}=137$} \\
\hline Educado/cordial & 32 & 45,1 & 24 & 33,8 & 40 & 53,3 & 50 & 36,5 \\
\hline Respondeu com presteza & 15 & 21,1 & 18 & 25,3 & 16 & 21,3 & 24 & 17,1 \\
\hline Clareza da informação & 16 & 22,5 & 17 & 23,9 & 11 & 14,7 & 16 & 11,7 \\
\hline Adequação técnica da informação & 9 & 12,7 & 5 & 7,0 & 6 & 8,0 & 24 & 17,1 \\
\hline Esclareceu às dúvidas & 11 & 15,5 & 8 & 11,3 & 16 & 21,3 & 34 & 24,8 \\
\hline $\begin{array}{l}\text { Outros aspectos da comunicação } \\
\text { competente }\end{array}$ & 9 & 12,7 & 11 & 15,5 & 5 & 6,7 & 14 & 10,2 \\
\hline Outros aspectos positivos & 4 & 5,6 & 11 & 15,5 & 8 & 10,7 & 18 & 13,1 \\
\hline Regular & \multicolumn{2}{|c|}{$\mathrm{n}=16$} & \multicolumn{2}{|c|}{$\mathrm{n}=19$} & \multicolumn{2}{|c|}{$\mathrm{n}=6$} & \multicolumn{2}{|c|}{$\mathrm{n}=7$} \\
\hline Não foi educado/cordial & 5 & 31,2 & 8 & 42,1 & 1 & 16,7 & 2 & 28,6 \\
\hline Atendimento de rotina & 5 & 31,2 & 9 & 47,4 & 0 & 0,0 & 1 & 14,2 \\
\hline Profissional incompetente & 3 & 18,7 & 0 & 0,0 & 1 & 16,7 & 2 & 28,6 \\
\hline Esclarecimento parcial das Dúvidas & 3 & 18,7 & 1 & 5,3 & 3 & 50,0 & 2 & 28,6 \\
\hline Outros aspectos & 1 & 6,2 & 3 & 15,8 & 1 & 16,7 & 0 & 0,0 \\
\hline
\end{tabular}

Nota: várias razões foram apresentadas pelos doadores para a percepção referida, motivo pelo qual a soma é superior a $100 \%$. 
Tabela 4. Motivos referidos pelos doadores, segundo o grau de confiança no atendimento em distintas etapas da doação de sangue. Hemocentro Recife, Brasil, 2008

\begin{tabular}{|c|c|c|c|c|c|c|}
\hline \multirow[t]{2}{*}{ Confiança no atendimento } & \multicolumn{2}{|c|}{$\begin{array}{c}\text { Triagem de } \\
\text { Enfermagem }\end{array}$} & \multicolumn{2}{|c|}{$\begin{array}{l}\text { Triagem } \\
\text { Médica }\end{array}$} & \multicolumn{2}{|c|}{$\begin{array}{l}\text { Sala de } \\
\text { coleta }\end{array}$} \\
\hline & $n^{\circ}$ & $\%$ & $n^{\circ}$ & $\%$ & $\mathrm{n}^{\circ}$ & $\%$ \\
\hline Confiança sentida & \multicolumn{2}{|c|}{$\mathrm{n}=527$} & \multicolumn{2}{|c|}{$\mathrm{n}=527$} & \multicolumn{2}{|c|}{$n=527$} \\
\hline Muito grande & 131 & 24,9 & 139 & 26,4 & 215 & 40,8 \\
\hline Grande & 321 & 60,9 & 328 & 62,2 & 251 & 47,6 \\
\hline Regular & 63 & 12,0 & 49 & 9,3 & 47 & 8,9 \\
\hline Pequena & 6 & 1,1 & 7 & 1,3 & 11 & 2,1 \\
\hline Nenhuma & 6 & 1,1 & 4 & 0,8 & 3 & 0,6 \\
\hline Muito grande/grande & \multicolumn{2}{|c|}{$\mathrm{n}=452$} & \multicolumn{2}{|c|}{$\mathrm{n}=467$} & \multicolumn{2}{|c|}{$\mathrm{n}=466$} \\
\hline Profissional competente & 239 & 52,9 & 152 & 32,5 & 160 & 34,3 \\
\hline Educado/cordial & 83 & 18,4 & 63 & 13,5 & 96 & 20,6 \\
\hline Confiança na instituição & 82 & 18,1 & 67 & 14,3 & 35 & 7,5 \\
\hline Atendimento rotineiro & 39 & 8,6 & 60 & 12,8 & 10 & 2,1 \\
\hline Perguntas/informações apropriadas ao doador & 26 & 5,7 & 51 & 10,9 & 7 & 1,5 \\
\hline Outros aspectos da comunicação competente & 14 & 3,1 & 42 & 9,0 & 0 & 0,0 \\
\hline Bom atendimento & 28 & 6,2 & 39 & 8,3 & 0 & 0,0 \\
\hline Atitude de cuidado & 33 & 7,3 & 17 & 3,6 & 35 & 7,5 \\
\hline Confiança na categoria profissional & 0 & 0,0 & 43 & 9,2 & 0 & 0,0 \\
\hline Compreensão da vivência do doador & 0 & 0,0 & 0 & 0,0 & 170 & 36,5 \\
\hline Ambiente físico & 0 & 0,0 & 0 & 0,0 & 55 & 11,8 \\
\hline Outros aspectos & 64 & 14,1 & 54 & 11,5 & 63 & 13,5 \\
\hline Regular & \multicolumn{2}{|c|}{$n=63$} & \multicolumn{2}{|c|}{$\mathrm{n}=50$} & \multicolumn{2}{|c|}{$\mathrm{n}=47$} \\
\hline Não foi educado/cordial & 21 & 33,3 & 17 & 34,0 & 2 & 4,2 \\
\hline Faltou pergunta/informação apropriada ao doador & 13 & 20,6 & 4 & 8,0 & 0 & 0,0 \\
\hline Não gostou da rapidez do atendimento & 0 & 0,0 & 17 & 34,0 & 0 & 0,0 \\
\hline Não efetuou atendimento rotineiro & 9 & 14,3 & 0 & 0,0 & 0 & 0,0 \\
\hline Atendimento de rotina & 0 & 0,0 & 6 & 12,0 & 4 & 8,5 \\
\hline Profissional competente & 7 & 11,1 & 0 & 0,0 & 3 & 6,4 \\
\hline Profissional incompetente & 6 & 9,5 & 0 & 0,0 & 0 & 0,0 \\
\hline Temor diante da situação & 0 & 0,0 & 0 & 0,0 & 27 & 57,4 \\
\hline Outros aspectos negativos & 6 & 9,5 & 8 & 16,0 & 9 & 19,1 \\
\hline Outros aspectos positivos & 3 & 4,8 & 0 & 0,0 & 5 & 10,6 \\
\hline
\end{tabular}

Nota: em cada faixa de confiança, várias razões foram apresentadas pelos doadores para a confiança referida, motivo pelo qual a soma é superior a $100 \%$.

relação com a unidade de hemoterapia, em comparação àquela existente entre paciente e serviço de saúde. Para Borges et al. ${ }^{4}$, tal diferença permite supor que a avaliação da satisfação do doador é menos afetada pelo fenômeno da alta satisfação conhecido como viés de gratidão que decorreria, sobretudo nos países em desenvolvimento e nos serviços públicos, da relutância em expressar opiniões negativas ${ }^{23}$. Sem temor de perder o direito ao serviço o doador estaria mais propenso a verbalizar as deficiências do acesso e do atendimento, contribuindo de forma mais efetiva para correção de rumos ${ }^{4,5}$.

As relações interpessoais, a comunicação e a qualidade técnica do atendimento foram mais satisfatórias durante o processo de trabalho de- senvolvido na SC, com os menores níveis de satisfação nos setores técnicos, apesar da boa avaliação, estando relacionado com a TE. Muito embora tenha sido feita uma diferenciação na avaliação dos doadores, à parte o turno de trabalho, sexo, antecedentes de doação e escolaridade, são os mesmos técnicos que atuam em regime de rodízio nos dois setores. Essa dessemelhança nos leva a interrogar sobre o grau de identificação com as tarefas realizadas na TE e recomenda iniciativas institucionais favoráveis à satisfação dos profissionais envolvidos e, por consequência, à maior aceitabilidade dos doadores.

Apesar das controvérsias acerca das relações entre gênero e satisfação dos usuários ${ }^{12,13}$, neste estudo, de acordo com aqueles que apontam a 
maior capacidade crítica das mulheres, nas avaliações influenciadas pelo gênero os homens revelaram uma percepção ainda mais positiva das etapas da doação. A opinião sobre a disponibilidade dos profissionais para esclarecer dúvidas foi similar, todavia, as mulheres solicitaram mais esclarecimentos, estimulando um olhar diferenciado sobre suas necessidades individuais. A maior percepção feminina acerca da centralidade do indivíduo nos processos de trabalho demanda particular atenção, já que, tanto no Brasil como em países desenvolvidos, existe a pretensão de ampliar a doação de sangue e torná-la de repetição entre as mulheres ${ }^{6}$.

Os doadores ressaltaram o fato dos profissionais terem sido educados e cordiais, mostrando presteza ao responder às perguntas, em uma atitude receptiva. É justamente a maneira agradável e atenciosa de tratar que demarca a diferença das idéias sobre o atendimento rotineiro, citado principalmente na TE e TM. De um lado, essa resposta justificou percepções positivas do tratamento recebido, remetendo ao desenvolvimento sistemático de procedimentos e atitudes que qualificam a atenção. De outro, explicou avaliações negativas decorrentes da percepção de que os profissionais restringiam suas ações a atitudes mecânicas. Nesses dois setores, a desatenção e a falta de cordialidade reduziram a confiança no atendimento.

Para Filgueiras e Deslandes ${ }^{16}$, o acolhimento implica em receptividade, escuta ativa e comunicação competente. Por meio da escuta ativa o profissional propicia espaço ao doador para expressar o que sabe, pensa e sente, adquirindo um maior conhecimento das suas necessidades e de como satisfazê-las. Foi principalmente nos setores técnicos que a opinião positiva decorreu da capacidade de escuta do profissional. A solicitação para esclarecer dúvidas foi maior na SC, etapa em que o temor relacionado aos procedimentos que envolvem sangue tornou-se mais premente. Não obstante, na SC a confiança no atendimento tenha decorrido, sobretudo, da compreensão da vivência do doador, o sentimento de medo que afetou essa confiança, em 7,2\% dos entrevistados, indicaria a necessidade de ampliar a escuta e de criar condições para que falassem desses temores, proporcionando maior apoio emocional.

Teixeira ${ }^{15}$ considera que a conversa é um dispositivo indispensável ao bom desempenho das atividades de saúde, já que nunca se cessa de negociar as necessidades que podem vir a ser satisfeitas pelo serviço. A comunicação competente não se atém a conteúdos de interesse dos profis- sionais, para obter informações que possibilitem avaliar a adequação clínica do doador ou fornecer orientações como parte do protocolo organizacional ${ }^{15,16,24}$. Os doadores tiveram uma percepção abrangente da competência comunicativa, dizendo-se satisfeitos quando as informações fornecidas ou as perguntas efetuadas levaram em conta suas necessidades e expectativas. Aspecto que despertou, inclusive, o sentimento de estar sendo cuidado. A clareza e o detalhamento permitiram a aquisição ou o reforço de conhecimentos.

A competência profissional foi um forte motivo para a confiança no atendimento. Contudo, em determinadas circunstâncias, a relação que se estabeleceu não foi entre profissional e doador, mas sim entre o doador e a credibilidade institucional. A confiança depositada pelo doador de sangue no hemocentro é fundamental, mas cabe refletir sobre o que motivou esse deslocamento de uma relação interpessoal capaz de acolher a singularidade para uma relação em que se é "todo aquele" que recebe atendimento. Essa perspectiva predominou na TE onde o desempenho foi menos satisfatório. A relação também pode se estabelecer entre o doador e a categoria profissional, como ocorreu na credibilidade referida ao médico.

Apesar das diferenças teórico-metodológicas, a avaliação realizada em 2007, no Hemocentro Recife, utilizando o IPPS, também encontrou uma grande satisfação, com destaque positivo para o atendimento prestado, a capacidade dos funcionários e o tratamento atencioso e respeitoso recebido pelo doador. Identificaram-se como aspectos negativos a falta de clareza e a simplicidade das explicações, o fornecimento de informações incorretas e incompletas, além de encontrarem dificuldades para conseguir o atendimento ${ }^{7}$. No estudo atual, como noutros ${ }^{4-6}$, a confiança na unidade, a competência, a velocidade de atendimento, a credibilidade e o acesso foram elementos importantes para a percepção do serviço.

$\mathrm{O}$ acesso geográfico, que pode ser avaliado pela caracterização da forma e do tempo de deslocamento e o acesso organizacional pelo tempo de espera no serviço têm representado um dos principais motivos de insatisfação para doadores de sangue ${ }^{4-6}$. Ao redor de $23,5 \%$ dos participantes demonstraram algum grau de insatisfação devido à dificuldade para chegar ao Hemocentro Recife. Metade teve uma percepção positiva do tempo gasto no processo de doação, traduzindo o confronto entre as expectativas do doador de ser acolhido e o tempo de espera na unidade. Sugere-se rever a adequação dos recur- 
sos ao volume da demanda e prestar esclarecimentos de forma sistemática ao doador acerca dos esforços empreendidos para reduzir o tempo total da doação, garantindo o respeito às necessidades individuais.

Via de regra, os pontos frágeis do atendimento diziam respeito à ausência ou insuficiência dos elementos que proporcionaram uma visão positiva como, por exemplo, impessoalidade do tratamento, falta de clareza ao informar, falta de perguntas e informações apropriadas, persistência de dúvidas e rapidez da entrevista médica. Para Kloetzel et al. ${ }^{25}$, é importante corrigir as deficiências apontadas pelos usuários, reconhecendo necessidades que poderiam ser julgadas secundárias, mas que teriam repercussões nada desprezíveis sobre a adesão aos serviços. Convém se atentar para a necessidade de se construir um relacionamento com o doador capaz de assegurar que o mesmo retorne voluntária e regularmente ao hemocentro.

Para caminhar nessa direção, um dos aspectos fundamentais é o aprimoramento da atenção centrada na pessoa, na troca de informações e saberes, na escuta de expectativas e de necessidades e no apoio emocional ${ }^{15,16,24}$, a qual requer um processo de educação continuada que articule a formação técnica, humanitária e ética dos profissionais. Por outro lado, não se deveria prescindir da busca de um maior conhecimento sobre as relações dos profissionais com o seu trabalho, visando simultaneamente favorecer a qualidade do atendimento e a satisfação de agentes do trabalho e doadores ${ }^{26}$.

É preciso lembrar que, neste estudo, apesar das restrições decorrentes do fato do método quantitativo minimizar a experiência subjetiva, buscou-se reduzir uma limitação importante desse tipo de abordagem, na medida em que foram levados em conta os critérios a que recorreram os doadores para julgar a experiência na doação atual ${ }^{27}$. Além disso, foram utilizados indicadores com capacidade de traduzir a especificidade de distintos elementos que conformam à aceitabilidade. Portanto, indicadores mais sensíveis para identificar, em um determinado contexto, tanto os aspectos que estão associados ao sentir-se com os valores e as expectativas correspondidos, quanto às mudanças que precisam ser efetuadas no serviço $^{28}$. Espera-se que os resultados possam apoiar concretamente a pretendida humanização das práticas em saúde.

\section{Colaboradores}

FMR Araújo participou da concepção do projeto, coleta, análise e interpretação dos dados, da redação do artigo e aprovou a versão a ser publicada. KVO Feliciano participou da concepção do projeto e análise e interpretação dos dados, da redação do artigo e aprovou a versão a ser publicada. MFM Mendes participou da análise e interpretação dos dados, realizou revisão crítica relevante do conteúdo intelectual e aprovou a versão a ser publicada. 


\section{Referências}

1. Sojka EN, Sojka P. The blood donation experience: self-reported motives and obstacles for donations blood. Vox Sanguinis 2008; 94(1):56-83.

2. Brasil. Ministério da Saúde (MS). Agência Nacional de Vigilância Sanitária (Anvisa). Fazendo a diferença: captando doadores voluntários de sangue. Brasília: Ministério da Saúde (MS); 2003.

3. World Health Organization (WHO). Blood transfusion safety. 2007. [acessado em 2007 maio 13]. Disponível em: http://www.who.int/bloodsafety/en/

4. Borges VL, Martinez EZ, Bendini MH, Costa MAGF, Ferreira SCL. Avaliação da fidedignidade de um instrumento voltado à satisfação do doador de sangue. Rev. bras. epidemiol. 2005; 8(2):177-186.

5. Santos EC, Condeço J. Avaliação do grau de satisfação dos doadores de sangue do Hospital Distrital de Chaves. ABO - Revista de Medicina Transfusional 2002; 11:5-12.

6. Ludwing ST, Rodrigues ACM. Doação de sangue: uma visão de marketing. Cad Saude Publica 2005; 21(3):932-939.

7. Universidade Federal de Pernambuco (UFPE). Fundação de Apoio ao Desenvolvimento. Pesquisa de satisfação dos clientes da Fundação Hemope. Recife: UFPE; 2007.

8. Angelim GP. Sistema nacional de avaliação da satisfação de usuários do serviço público. VII Congreso Internacional del CLADE sobre la Reforma del Estado y de la Administración Pública. 2002 [acessado 2008 out 12]. Disponível em: http://www. unpan 1.un.org/intradoc/groups/public/documents/ CLAD/clad0043719.pdf.

9. Uchimura KY, Bosi MLM. Qualidade e subjetividade na avaliação de programas e serviços em saúde. Cad Saude Publica 2002; 18(6):1561-1569.

10. Donabedian A. The seven pillars of quality. Arch. Pathol. Lab. Med. 1990; 114(11):1115-1118.

11. Acurcio FA, Cherchiglia ML, Santos MA. Avaliação de qualidade de serviços de saúde. Saúde em Debate 1991; 33:50-53.

12. Espiridião MA, Trad LAB. Avaliação de satisfação de usuários: considerações teórico-conceituais. Cad Saude Publica 2006; 22(6):1267-1276.

13. Vaitsman J, Andrade GRB. Satisfação e responsividade: formas de medir a qualidade e a humanização da assistência à saúde. Cien Saude Colet 2005; 10(3):599-611.

14. Brasil. Ministério da Saúde (MS). Secretaria Executiva. Núcleo Técnico da Política Nacional de Humanização. Humaniza SUS: Política Nacional de Humanização. Brasília: Ministério da Saúde (MS); 2004.

15. Teixeira RR. O acolhimento num serviço de saúde entendido como uma rede de conversações. In: Pinheiro R, Mattos RA, organizadores. Construção da integralidade: cotidiano, saberes e práticas em saúde. Rio de Janeiro: UERJ; 2003. p. 89-111.

16. Filgueiras SL, Deslandes SF. Avaliação das ações de aconselhamento. Análise de uma perspectiva de prevenção centrada na pessoa. Cad Saude Publica 1999; 15(Supl.2):121-131.
17. Brasil. Ministério da Saúde (MS). Agência Nacional de Vigilância Sanitária. Perfil do doador de sangue brasileiro. Brasília: Ministério da Saúde (MS); 2004. [acessado 2007 maio 20]. Disponível em: http://www. anvisa.gov.br/hotsite/doador_sangue/abertura. html

18. Suárez IMB, Fernández-Montoya A, Fernández AR, Lópes-Berrio A, Cillero-Peñuella M. How regular blood donors explain their behavior. Transfusion 2004; 44(10):1441-1446.

19. Schreiber JB, Sanchez AM, Glynn AS, Wright DJ. Increasing blood availability by changing donation patterns. Transfusion 2003; 43(5):591-597.

20. Marconi MA, Lakatos EM. Técnicas de Pesquisa. 2a ed. São Paulo: Atlas; 1990

21. Brasil. Ministério da Saúde (MS). Agência Nacional de Vigilância Sanitária (Anvisa). RDC n ${ }^{0}$ 153, de 14 de junho de 2004. [acessado 2008 jun 5]. Disponível: http://e-legis.anvisa.gov.br/leisref/public/ showAct.php?id=11662\&word=

22. Gomes R, Silva CMFP, Deslandes SF, Souza ER. Avaliação da assistência ambulatorial a portadores de HIV/AIDS no Rio de Janeiro, segundo a visão de seus usuários. Cad Saude Publica 1999; 15(4):789-797.

23. Espiridião M, Trad LAB. Avaliação de satisfação de usuários. Cien Saude Colet 2005; 10(Supl.):303-312.

24. Rossi FR, Lima MADS. Acolhimento: tecnologia leve nos processos gerenciais do enfermeiro. Rev Bras Enferm 2005; 58(3):305-310.

25. Kloetzel K, Bertoni AM, Irazoqui MC, Campos VPG, Santos RN. Controle de qualidade em atenção primária à saúde. I - A satisfação do usuário. Cad Saude Publica 1998; 14(3):623-628.

26. Ferreira MC, Assmar EML. Cultura, satisfação e saúde nas organizações. In: Tamayo, A, organizador. Cultura e saúde nas organizações. Porto Alegre: Artmed; 2004. p. 102-126.

27. Assis SG, Deslandes SF, Minayo MCS, Santos NC. Definição de objetivos e construção de indicadores visando à triangulação. In: Minayo MCS, Assis SG, Souza ER, organizadores. Avaliação por triangulação de métodos: abordagem de programas sociais. Rio de Janeiro: Editora Fiocruz; 2005. p.105-132.

28. Robles-Garcia M, Dierssen-Sotos T, MartinezOchoa E, Herrera-Carral P, Díaz-Mendi AR, Llorca-Díaz J. Variables relacionadas com la satisfacción laboral: un estudio transversal a partir del modelo EFQM. Gaceta Sanitaria 2005; 19(2):127-134.

Artigo apresentado em 19/06/2009

Aprovado em 23/01/2010

Versão final apresentada em 05/02/2010 